\title{
Reconversion of neurosurgical practice in times of the SARS-CoV-2 pandemic: a narrative review of the literature and guideline implementation in a Mexican neurosurgical referral center
}

\author{
Sergio Díaz-Bello, MD,,3 Alan Hernández-Hernández, MD,,3 Gerardo Y. Guinto-Nishimura, MD,,3 \\ Michel G. Mondragón-Soto, MD, ,,3 Monica Lem-Carrillo, MD, ,,3 Alberto González-Aguilar, MD, ${ }^{2,3}$ \\ Juan M. Calleja-Castillo, MD, ,,3 Adolfo Leyva-Rendón, MD, ${ }^{3}$ Pablo León-Ortiz, MD, PhD, ${ }^{3}$ \\ Carmen M. Chávez-Piña, MD, ${ }^{3,4}$ Gustavo A. Pando-Tarín, MD, ,,4 Sonia I. Mejía-Pérez, MD, ${ }^{3,5}$ \\ Jesús Taboada-Barajas, MD, ${ }^{3,6}$ Elsa D. Zavala-Álvarez, MD, ${ }^{3,7}$ José L. Soto-Hernández, MD, ,7 \\ Graciela Cárdenas, MD, ${ }^{3,7}$ and Juan L. Gómez-Amador, MD ${ }^{1,3}$
}

Departments of ${ }^{1}$ Neurosurgery, ${ }^{2}$ Neurological Emergencies, ${ }^{4}$ Neuroanesthesiology, ${ }^{5}$ Medical Education, ${ }^{6}$ Neuroradiology, and ${ }^{7}$ Neuro-Infectious Diseases, ${ }^{3}$ Instituto Nacional de Neurología y Neurocirugía "Manuel Velasco Suárez," Mexico City, Mexico

OBJECTIVE The coronavirus disease 2019 (COVID-19) pandemic has forced the modification of surgical practice worldwide. Medical centers have been adapted to provide an efficient arrangement of their economic and human resources. Although neurosurgeons are not in the first line of management and treatment of COVID-19 patients, they take care of patients with neurological pathology and potential severe acute respiratory syndrome coronavirus 2 (SARSCoV-2) infection. Here, the authors describe their institutional actions against the pandemic and compare these actions with those in peer-reviewed publications.

METHODS The authors conducted a search using the MEDLINE, PubMed, and Google Scholar databases from the beginning of the pandemic until July 11, 2020, using the following terms: "Neurosurgery," "COVID-19/SARS-CoV-2," "reconversion/modification," "practice," "academy," and "teaching." Then, they created operational guidelines tailored for their institution to maximize resource efficiency and minimize risk for the healthcare personnel.

RESULTS According to the reviewed literature, the authors defined the following three changes that have had the greatest impact in neurosurgical practice during the COVID-19 pandemic: 1) changes in clinical practices; 2) changes in the medical care setting, including modifications of perioperative care; and 3) changes in the academic teaching methodology. CONCLUSIONS The Instituto Nacional de Neurología y Neurocirugía "Manuel Velasco Suárez" is one of the major referral centers for treating highly complex neurosurgical pathologies in Mexico. Its clinical and neurosurgical practices have been modified with the implementation of specific interventions against the spread of COVID-19. These practical and simple actions are remarkably relevant in the context of the pandemic and can be adopted and suited by other healthcare centers according to their available resources to better prepare for the next event.

https://thejns.org/doi/abs/10.3171/2020.9.FOCUS20553

KEYWORDS COVID-19 pandemic; neurosurgery; modification/retraining; actions; SARS-CoV-2

$\mathrm{T}$ HE coronavirus disease 2019 (COVID-19) pandemic has taken the entire world by surprise, with an unmeasurable loss of life and an unprecedented impact on the world economy. By July 11, 2020, there had been $12,322,395$ confirmed cases and 556,335 casualties world- wide and 6,397,230 confirmed cases in the Americas. In Mexico, there had been 332,929 cases with 36,603 deaths. ${ }^{1}$

COVID-19 is caused by the severe acute respiratory syndrome coronavirus 2 (SARS-CoV-2). Since the first published case reports in December 2019 of atypical pneu-

ABBREVIATIONS ACS $=$ American College of Surgeons; CO-RADS = COVID-19 Reporting and Data System; COVID-19 = coronavirus disease 2019; PPE = personal protective equipment; RT-PCR = reverse-transcription polymerase chain reaction; SARS-CoV-2 = severe acute respiratory syndrome coronavirus 2. SUBMITTED June 14, 2020. ACCEPTED September 23, 2020. INCLUDE WHEN CITING DOI: 10.3171/2020.9.FOCUS20553. 
monia in Wuhan City, China, ${ }^{2}$ the infection has become a rapidly spreading disease and was declared a pandemic by the WHO on March 11, 2020. ${ }^{3}$

In Mexico City, the first case was confirmed on February 24, 2020; a few hours later, another case was confirmed in the state of Sinaloa and then a third case, again in Mexico City. ${ }^{5}$ The first COVID-19-related death occurred on March 18, 2020. ${ }^{6}$ By the end of May, the confirmed cases in Mexico were concentrated mainly in the State of Mexico, Baja California, Sinaloa, Veracruz, and Puebla. However, almost all states had reported cases of COVID-19?

During the pandemic, neurosurgeons have coped with several issues in their practice, such as canceling elective cases and outpatient care by reducing hospital staff to minimize the amount of potential exposure, selection and management of neurosurgical emergencies only, and changes in academic teaching and training methods for residents..$^{8-10}$

In the following text, we share our institutional experience based on the current international literature as an example and a basis for other resource-constrained neurosurgical centers.

\section{Methods}

A review was performed by searching the MEDLINE, PubMed, and Google Scholar databases from the beginning of the pandemic until July 11,2020, using the following terms: "Neurosurgery," "COVID-19/SARS-CoV-2," "reconversion/modification," "practice," "academy," and "teaching." Only articles of the adult population in the English language as well as epidemiological information from Mexico and Latin America in Spanish were included. Studies related to pediatric neurosurgery were excluded.

\section{Results}

According to the reviewed literature, the main adopted strategies on neurosurgical practice during the COVID-19 pandemic were the following: 1) changes in clinical practices; 2) changes in the medical care setting with modifications of preoperative, perioperative, and postoperative care; and 3) changes in medical education and training methods. This information was combined to develop algorithms implemented at our institution that may be useful for other neurosurgical services (Figs. 1 and 2).

\section{Staff Operational Changes}

Considering that SARS-CoV-2 RNA is detected in the respiratory tract, feces, blood, and CSF and its neuroinvasiveness in the olfactory epithelium, COVID-19 is considered a highly transmissible person-to-person disease. Therefore, one policy is to avoid large crowds..$^{11-14}$

Hospitals across the US implemented several measures, such as temperature checks for employees and no-visitor policies for patients to limit cross-infection between patients and healthcare workers. ${ }^{15}$ In China, 3.8\% ( $\mathrm{n}=1716$ of 44,672) of COVID-19 cases occurred in healthcare personnel, $14.8 \%(\mathrm{n}=254)$ of which were severe; in Lombardy, Italy, $20 \%$ of the cases occurred in healthcare work- ers. ${ }^{16,17}$ Subsequent reports suggested that the first nosocomial spread event occurred during pituitary surgery in which 14 people were exposed and infected in China. ${ }^{18}$

\section{Changes in Healthcare}

On March 13, 2020, the American College of Surgeons (ACS) issued an unprecedented recommendation to "minimize, postpone, or cancel electively scheduled procedures." As the number of COVID-19 cases increased in the US, the American Hospital Association and the Centers for Medicare \& Medicaid Services quickly followed the ACS guidelines and issued similar recommendations. ${ }^{19-21}$

Different survey-based strategies and scales have been created, such as consulting neurosurgeons' opinions about the risk of postponing the management of certain diseases. In Italy, some centers were chosen to classify neurosurgical emergencies by temporality into groups of 0 to 6 hours, 6 to 48 hours, 48 hours to 14 days, and $>14$ days to define which patients should be taken to the operating room immediately (0-6 hours) and which patients would benefit from evaluation at a designated COVID-19 center before any intervention. ${ }^{23}$

On May 15, 2020, an Indian consensus for the practice of neurology and neurosurgery provided recommendations for the management of these patients. In their recommendations, the authors declared that patients should be classified according to surgical priority as having acute (requiring immediate treatment, surgery within 24 hours), subacute (requiring treatment within a maximum of 7-10 days), or chronic (requiring treatment within 1 month) conditions. ${ }^{24,25}$

Finally, recommendations of the ACS and the European Association of Neurosurgical Societies have been issued for each hospital, healthcare system, and surgeon to carefully review scheduled elective procedures with a plan to minimize elective surgeries and to postpone or cancel scheduled operations, endoscopies, or other procedures..$^{26}$ COVID-19 has dramatically altered surgical practice patterns worldwide in a short time since the first cases appeared; therefore, the first studies have been published based on experiences and recommendations, predominantly from places initially and substantially affected by the COVID-19 crisis, including China, ${ }^{27-29}$ Singapore, and northern Italy. ${ }^{30-33}$

\section{Perioperative Management}

\section{Preoperative Management}

In China, the surgical indications are rigorously evaluated by the surgical team to determine emergency conditions. Non-emergency consultations are documented and followed up through telemedicine or phone calls. ${ }^{29}$ Telemedical care was reported to have increased in some centers by up to $33 \% .^{34}$

During the preoperative period, a thoracic CT scan and nucleic acid sequencing (reverse-transcription polymerase chain reaction [RT-PCR]) are performed for the preliminary diagnosis of COVID-19; however, the chances of a false-negative test result have been reported to be as high as $16.7 \% .{ }^{17}$ Patients with positive results are identified as having confirmed COVID-19, and patients with prelimi- 


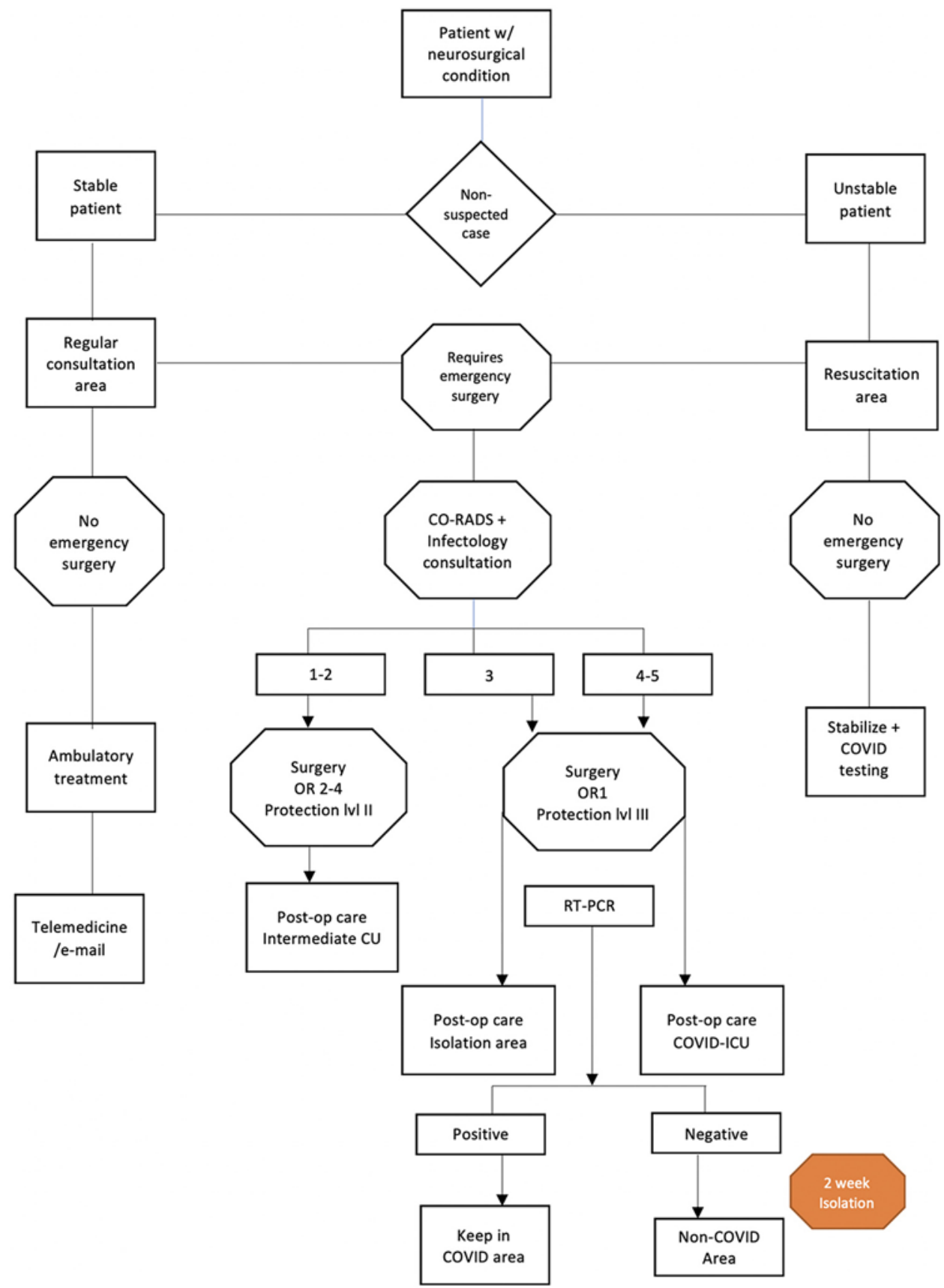

FIG. 1. Algorithm 1. Management of patients not suspected of having COVID-19. Conditions requiring surgery include acute hydrocephalus, postsurgical infection, subarachnoid hemorrhage, endocranial hypertension of tumor origin, compressive spinal cord disease, and traumatic surgical pathology. $\mathrm{CU}=$ care unit; $\mid \mathrm{vl}=$ level; $\mathrm{OR}=$ operating room.

nary negative results are considered suspect for having COVID-19. Therefore, various levels of protection and specific adaptations to operating rooms occur in a negative pressure environment with access routes specifically designated for all suspect or confirmed cases. ${ }^{30}$

On April 26, 2020, Singapore issued specific recommendations to the neurosurgical field in which it was emphasized that, depending on epidemiology and local resources, RT-PCR should be conducted in all patients prior to surgery for detection of SARS-CoV-2. All patients (even if asymptomatic) were considered as potentially infected..$^{31,32,35}$

\section{Intraoperative Management}

The following three environments are considered when the risk of transmission of SARS-CoV-2 in the operating room is high: $30,31,36$

1) all surgeries in which healthcare workers might be exposed to the respiratory or digestive tract; ${ }^{36}$ 


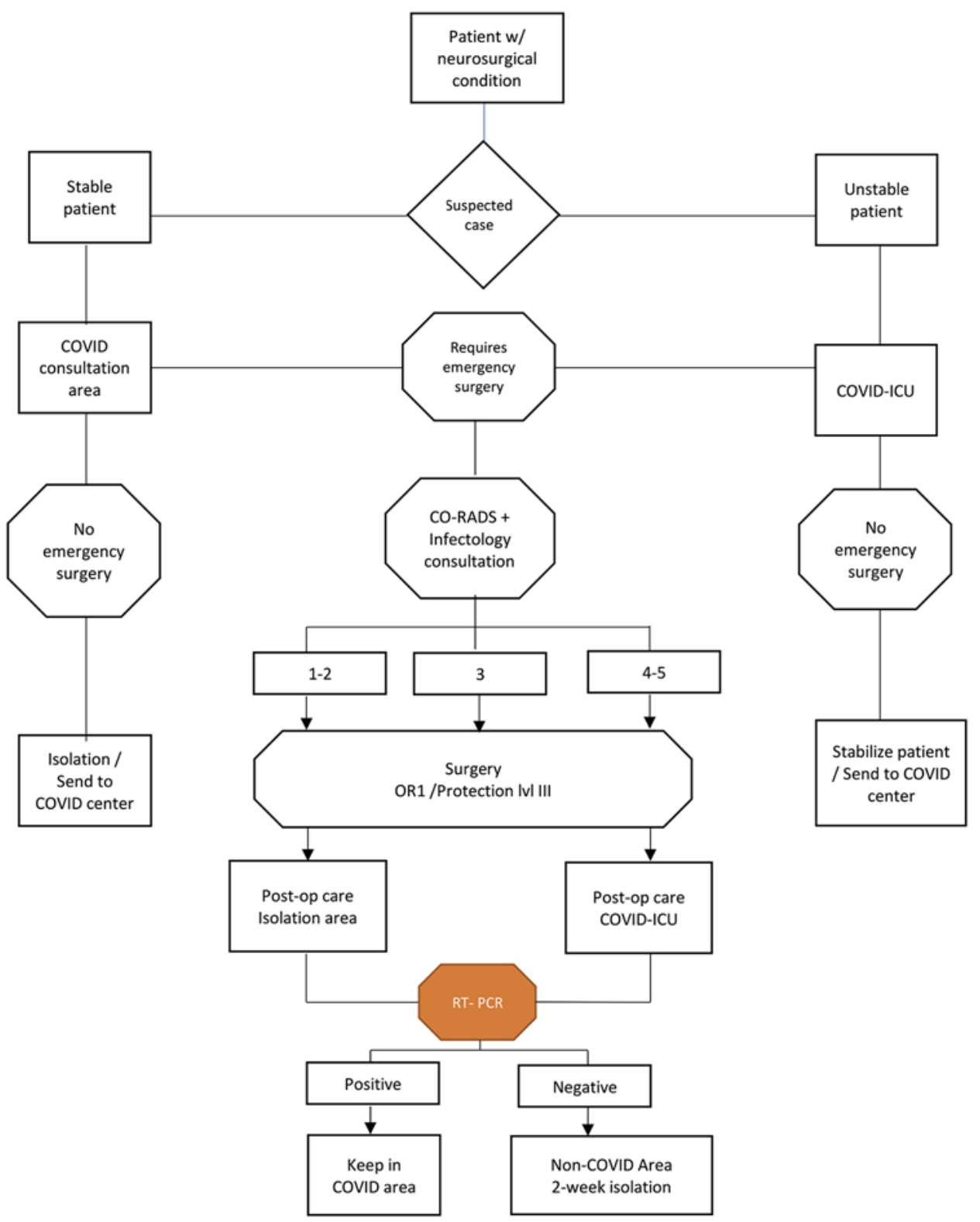

FIG. 2. Algorithm 2. Management of patients suspected of having COVID-19. Conditions requiring emergency surgery include hydrocephalus, postsurgical infection, subarachnoid hemorrhage, intracranial hypertension secondary to a neoplasia, compressive medullary disease, and trauma.

2) endotracheal intubation and extubation; 37,38

3) all surgical procedures with aerosol-generating instruments from potentially virion-contaminated tissues; at this point, it is recommended to limit the use of these devices (motorized drills, electrocautery, ${ }^{39-42}$ lasers, ${ }^{43}$ and ultrasonic aspirators). ${ }^{44}$

Given that most hospital settings have multiple operating rooms, it is highly recommended that all COVID-19confirmed and COVID-19-suspect patients are confined to designated operating rooms. ${ }^{45}$

\section{Postoperative Management}

After the surgical procedure was complete, patients were taken to a negative pressure procedure room where tracheal extubation was performed by the anesthesiology team wearing full protective gear..$^{15}$ Patients who had negative test results preoperatively can then be transferred to the general recovery room for postoperative management. Daily assessment of body temperature and respiratory symptoms is mandatory. ${ }^{46}$ Moreover, daily assessment of the body temperature of healthcare staff who are exposed to COVID-19-suspect patients should be implemented. ${ }^{46,47}$

\section{Change in the Academic and Training Methods of Neurosurgical Residents}

The current immediate devastating effects of the pan- 
TABLE 1. Procedures performed in evaluation and observation areas of suspected or confirmed COVID-19 patients

\begin{tabular}{|c|c|c|}
\hline Zone \& Risk of Contagion & Level of Risk \& Hospital Areas & Protection \& PPE Levels \\
\hline Green zone: mild risk & $\begin{array}{l}\text { Staff, patients, \&/or visitors are considered to be at equal risk of } \\
\text { COVID-19 infection as the general population: screening area, } \\
\text { hospital access, common areas w/in the institution }\end{array}$ & $\begin{array}{l}\text { Protection level I: attire w/ surgical uniform, exclusive } \\
\text { shoes for hospital use, clinical lab coat, mandatory } \\
\text { face mask }\end{array}$ \\
\hline $\begin{array}{l}\text { Yellow zone: moderate } \\
\text { risk }\end{array}$ & $\begin{array}{l}\text { Staff, patients, \&/or visitors are considered to be at higher risk of } \\
\text { COVID-19 infection than the general population: medical offices, } \\
\text { clinics, ORs, ICU, non-COVID-19 intermediate care unit, hospi- } \\
\text { talization areas, MRI room, non-COVID-19 CT scanner room }\end{array}$ & $\begin{array}{l}\text { Protection level II: attire w/ surgical uniform, exclusive } \\
\text { shoes for hospital use, clinical lab coat, N95 face } \\
\text { mask (mandatory use), examination gloves (1 set), } \\
\text { goggles }\end{array}$ \\
\hline Red zone: high risk & $\begin{array}{l}\text { Staff, patients, \&/or visitors are considered to be at high risk of } \\
\text { COVID-19 infection \& positive diagnosis of COVID-19: monitor- } \\
\text { ing area \& COVID-19 care hospitalization area, hospitalization } \\
\text { area for highly suspicious patients, area for aerosol-producing } \\
\text { procedures, ORs, CICU }\end{array}$ & $\begin{array}{l}\text { Protection level III: attire w/ surgical uniform, } \\
\text { exclusive shoes for hospital use, N95 face mask } \\
\text { (mandatory use), examination gloves (2 sets), } \\
\text { goggles, disposable impervious coat or overall suit, } \\
\text { protective face shield, suit up/suit off protocol }\end{array}$ \\
\hline
\end{tabular}

$\mathrm{CICU}=$ COVID-19 ICU; OR = operating room.

demic not only are evident in the economic and health systems but they also create obstacles in the medicine education programs, including the education of neurosurgical residents. ${ }^{48}$

In this regard, authors at the University Hospitals Cleveland Medical Center in the US reported that resident staffing decreased by $50 \%$, allowing teams to rotate for a week at a time with other residents staying at home and away from exposure. ${ }^{49}$

Of the actions undertaken at the Massachusetts General Hospital and Brigham and Women's Hospital, two focused on academic and learning aspects, such as implementing remote work for clinicians, residents, and support staff, and creating new virtual educational programs for residents. ${ }^{50}$ For resident education, a small proportion (12\%) reported cancellation of all instructional sessions within the department while the remaining suggested successful use of a videoconference-based format..$^{51}$

Despite the fact that virtual neurosurgical teaching cannot replace practical training, several centers implemented day-to-day strategies to combine the instructional, clinical, and surgical experience through the use of teleconferences concerning specific neurosurgical topics to continue the evaluation of students. ${ }^{52-54}$

\section{Experience With Implemented Strategies at the National Institute of Neurology and Neurosurgery of Mexico}

The Instituto Nacional de Neurología y Neurocirugía "Manuel Velasco Suárez," a highly specialized neurological and neurosurgical center in Mexico, was designated by the Mexican health secretary as a non-COVID hospital. ${ }^{55}$ Our center implemented specific clinical and hospital procedures for the care of COVID-19-confirmed or COVID-19-suspected infections. These approaches in combination with national guidelines were adapted to our neurosurgical department considering our resources in a limited-budget environment.

\section{Changes to Staff Practice}

One applied maneuver (a "worldwide contingency strat- egy") was to suspend elective admissions to hospitalization services, as well as ambulatory care, and thus provide only emergency care. At the same time, medical staff prone to developing a serious case of COVID-19 (those with diabetes, hypertension, and immunodeficient conditions) were temporarily withdrawn from hospital activities. New areas were adapted to concentrate COVID-19-confirmed and COVID-19-suspect patients. These areas were strategically separated from those for neurological patients who were not diagnosed with COVID-19. Similarly, exclusive areas were adapted to perform laboratory and imaging studies for both kinds of patients.

\section{Changes in the Healthcare System}

In the face of the pandemic, to diminish exposure and contagion risk, the hospital implemented communication through email, phone calls, and video calls to be able to review patients in stable neurosurgical condition. This strategy allowed safe evaluation of patients prior to their relocation. Screening personnel were placed at all hospital entrances to quickly identify suspect cases of COVID-19 before they were admitted to the hospital grounds. Upon evaluation by the screener, a patient was classified as having a suspect, probable, or confirmed COVID-19 diagnosis according to WHO operational definitions. ${ }^{56} \mathrm{~A}$ patient with suspected or confirmed COVID-19 was immediately sent to the emergency area for evaluation.

To perform these evaluations, some levels of care and protection were established (Table 1). The filter staff then transferred the patient to the appropriate place for them to receive care (Table 2). Surgical indications were rigorously evaluated by the on-call surgical team available 24 hours a day according to the Mexican Society of Neurological Surgery guidelines, as follows: ${ }^{57}$

1) class $\mathrm{A}++$ (requiring immediate or urgent treatment): patients with acute intracranial (rapidly evolving intracranial hypertension with impaired consciousness) or compressive spinal cord pathology;

2) class $A+$ (requiring treatment within a maximum of 7-10 days): for example, intracranial tumors with mass effect or progressive neurological deficit without al- 
TABLE 2. Clinical data for destination assignment for COVID-19-suspected cases

\begin{tabular}{lc}
\hline \multicolumn{1}{c}{ Clinical Data } & Destination \\
\hline $\begin{array}{l}\text { Patient or family member w/ significant clinical RS or fever w/ neurosurgical, neurological, or } \\
\text { psychiatric disease; clinically stable }\end{array}$ & $\begin{array}{c}\text { Red zone: consultation rooms w/in the } \\
\text { COVID-19 area }\end{array}$ \\
\hline $\begin{array}{l}\text { Patient or family member w/o RS or fever w/ neurosurgical, neurological, or psychiatric disease; } \\
\text { clinically stable }\end{array}$ & $\begin{array}{c}\text { Yellow zone: non-COVID-19 consultation } \\
\text { rooms w/in emergency department }\end{array}$ \\
\hline $\begin{array}{l}\text { Patient w/ low suspicion of COVID-19 w/ neurosurgical, neurological, or psychiatric disease; } \\
\text { clinically unstable requiring airway management }\end{array}$ & Yellow zone: resuscitation area \\
\hline $\begin{array}{l}\text { Patient or family member w/ significant RS or fever w/ neurosurgical, neurological, or psychiatric } \\
\text { disease; high suspicion or confirmed COVID-19; clinically unstable requiring airway management }\end{array}$ & Red zone: CICU \\
\hline $\begin{array}{l}\text { Patient or family member w/ high suspicion of or confirmed COVID-19 w/o urgent neurological, neuro- } \\
\text { surgical, or psychiatric condition }\end{array}$ & Red zone: COVID-19 hospitalization area \\
\hline
\end{tabular}

RS = respiratory symptoms

Stable and unstable patients without respiratory symptoms or low suspicion of COVID-19 are assigned to the yellow zones, considered to be low-intermediate risk areas. Stable and unstable patients with significant clinical respiratory symptoms or confirmed COVID-19 cases are assigned to the red zones.

tered mental status and having a forthcoming surgical procedure;

3) class A (requiring treatment within 1 month): neurosurgical pathology such as a neurological deficit that does not require urgent treatment.

Our hospital suspended surgeries of high aerosol-producing procedures such as transsphenoidal and transmastoid surgeries. In these situations, whenever necessary, patients were required to have negative results on two COVID-19 tests before entering the operating room, and surgical procedures were performed with mandatory use of personal protective equipment (PPE) level III (Fig. 3).

\section{Preoperative Period}

Our institution adopted thoracic CT screening as an initial evaluation before the COVID-19 PCR test. CT imaging was jointly evaluated by neuroradiology, infectology, and intensive care specialists based on several items: the COVID-19 Reporting and Data System (CO-RADS) $)^{58,59}$ classification (Supplemental Table 1), key clinical data (e.g., respiratory symptoms, fever, and diarrhea), and laboratory parameters (total leukocyte and lymphocyte counts and C-reactive protein, erythrocyte sedimentation rate, Ddimer, ferritin, and lactate dehydrogenase levels).

During the surgical procedure, patients with suspected or indeterminate COVID-19 (CO-RADS category $\geq 3$ ) were considered to pose a high risk of being contagious for the surgical staff; therefore, the use of PPE level III was mandatory. Patients with a CO-RADS category $\leq 2$ without respiratory symptoms were considered to be at a low risk of being contagious. Given our limited resources and the emergency situation, RT-PCR COVID-19 testing was postponed until the time of surgery. After testing, a path was cleared from the patient location (either emergency department or ICU) to the operating room to minimize exposure to employees.

Our hospital has 4 neurosurgical operating rooms. Patients at low risk of being contagious were attended at rooms 2, 3, and 4 using PPE level II. In contrast, those at high risk of being contagious were operated on in room 1 using PPE level III.

\section{Intraoperative Period}

During endotracheal intubation, the neuroanesthesiology team follows the consensus of the Society for Neuroscience in Anesthesiology and Critical Care and the Society of Vascular and Interventional Neurology guidelines, using acrylic boxes that isolate the head and neck of the patient during orotracheal intubation by the neuroanesthesiologist, with rapid intubation sequence through video laryngoscopy techniques. ${ }^{60-62}$ In all neurosurgical procedures, when possible, the use of aerosol-generating instruments was limited, and an experienced neurosurgeon always led surgical procedures in accordance with preoperative strategies (for reducing bleeding and long surgical procedures). Many adaptations were made (e.g., the use of aspiration at all times while using monopolar and/or bipolar coagulation).

\section{Postoperative Period}

All surgical staff discarded their worn robes and gloves securely in the operating room and performed strict hand hygiene before leaving the operating room. To achieve patient transport to the COVID-19-isolated areas, the activation of an internal security code was required to ensure the route and the appropriate cleaning and decontamination maneuvers.

A minimum of 2 hours between surgical procedures was planned to allow the operating room staff time to prepare for a subsequent intervention. During that lapse, rigorous decontamination of the walls, screens, keyboard, cables, monitors, and anesthesia machine was performed. After surgery, patients with a high risk of being contagious were moved to the COVID-19-isolated areas depending on their postoperative status and the need for an advanced airway. In these areas, patients with a pending COVID-19 test were closely clinically monitored and underwent chest CT scanning multiple times.

\section{Academic and Teaching Aspects}

At the beginning of the second half of March, our hospital announced the temporary cessation of all academic activities due to the concentration of training residents and 


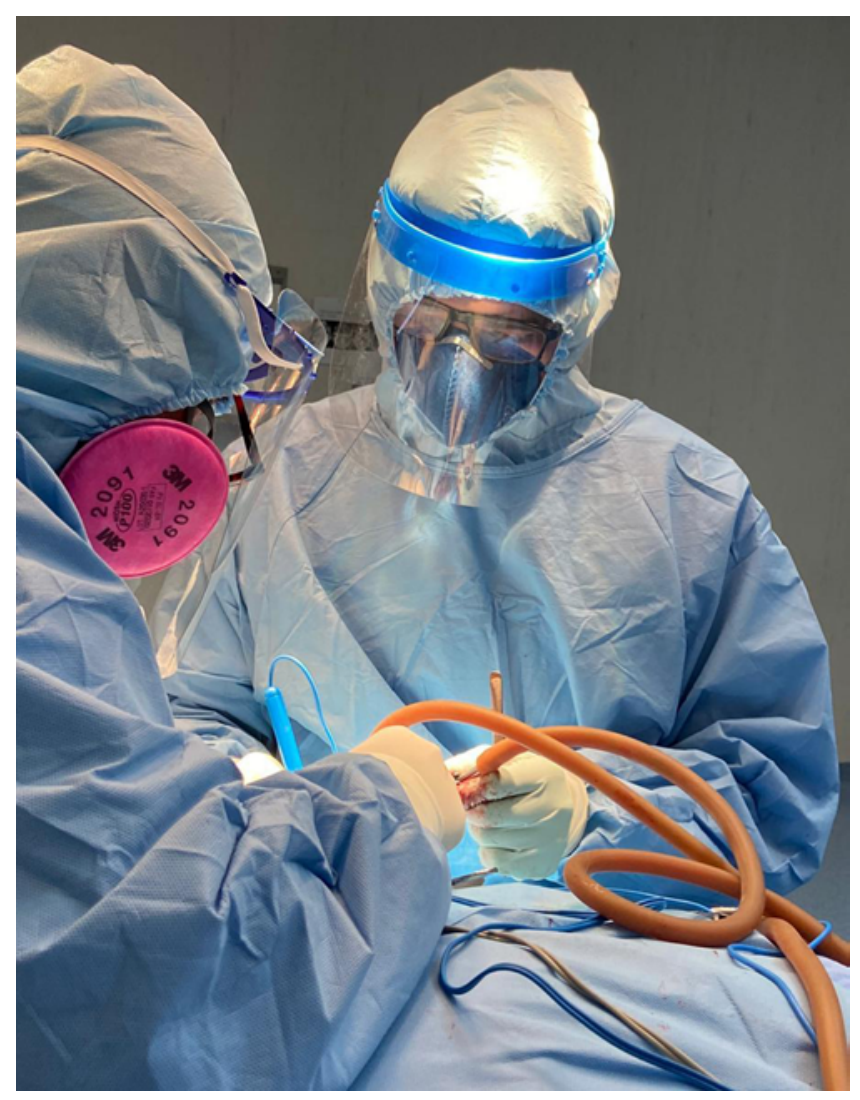

FIG. 3. Proper use of PPE level III in neurosurgical practice with a COVID-19-positive patient.

students in closed spaces. Remote education programs were implemented through virtual educational web-based platforms. All assessment evaluations continued according to previous academic plans.

In the neurosurgery service, a homework scheme was implemented, all journal club sessions were continued, and patient assistance was provided for those who had high-priority surgeries. Resident physicians continued local and national collegiate clinical case sessions with other neurosurgical centers. In addition, there were weekly support neuropsychological sessions for training residents to deal with stress or burnout syndrome. Training in the experimental laboratory with animal models was temporarily canceled in our hospital until epidemiological phase 3 was instituted and national infectious cases declined. Surgical practice for training residents was limited to emergency surgeries with a limited number of residents (senior residents) per procedure.

Despite these changes, the remote education program allowed training residents to continue the academic program on time, which guarantees their timely graduation and conclusion of training programs.

\section{Early Results of Our Implemented Actions}

The pandemic changed our practice to protect both patients and staff from infection. We oversaw several significant changes to our neurosurgical practice. For example, we used designated areas for infected patients and created supplementary ICUs and emergency triage, among other action, which has resulted in only 41 workers becoming infected since the beginning of the pandemic (10.9\% of all active personnel at our institution), including resident physicians (19.5\%), nurses (60.9\%), and support services (e.g., administrative staff, stretcher bearers, and nutritionists). Only $30 \%$ of our neurosurgical team was redistributed into COVID-19 medical teams, justifying a rationalization of resources. In addition, only about $21 \%$ of the neurosurgery residents have been in quarantine or isolation, taking into account that our hospital is at the center of the pandemic.

\section{Discussion}

At our institution, facing the COVID-19 pandemic has posed a great challenge for all healthcare staff, mainly in terms of adapting and reconverting our hospital setup and practice methods while continuing to treat patients with neurosurgical pathology uninterruptedly.

Some groups in the US ${ }^{8,22}$ used review panels, checklists, and support questionnaires to perform adequate selection of neurosurgical emergencies, taking into account the knowledge of the underlying pathology and the clinical patient condition at the time of assessment. A similar routine was followed in a general hospital (Fray Antonio Alcalde) in Guadalajara, Mexico, and by the Indian consensus of neurology and neurosurgery practices that were used to estimate the urgency of the surgery. ${ }^{24,25}$ At our institution, the neurosurgical service follows the proposed strategies (algorithms 1 and 2), but, when necessary, each neurosurgical patient was individualized and evaluated in real time given that a large number of neurosurgical pathologies have an unpredictable nature and often need surgical intervention. Moreover, there are patients who do not require emergency neurosurgical management but require hospitalization for the treatment of metabolic, fluid, or electrolyte imbalances and other medical complications.

Regarding COVID-19 testing in patients, we are gathering all efforts to obtain test results of the nucleic acid sequencing test for the detection of SARS-CoV-2 in a timely fashion, trying to adapt a diagnostic algorithm as proposed by Tan et al. ${ }^{63}$ The chest $\mathrm{CT}$ approach has a high sensitivity in detecting patients with moderate to severe COVID-19. One study showed a high positive predictive value and an area under the curve of 0.91 (95\% CI 0.85-0.97) for predicting an RT-PCR result and 0.95 (95\% CI 0.91-0.99) for the clinical diagnosis of COVID-19. ${ }^{8}$ Also, results of decision tree analysis demonstrate that incorporating chest CT scanning within the urgent imaging protocol used to evaluate neurosurgical patients is a better strategy than not performing such a scan. ${ }^{64}$

Worldwide, there have been several changes in neurosurgical training during the COVID-19 pandemic. ${ }^{49,50}$ Our institution also modified resident education programs despite strict distancing actions by the medical and resident training staff. All academic programs embraced virtual sessions through videoconferencing technology or Neurocampus sessions to decrease the risk of exposure. All work in the simulated neurosurgical area required appropriate distancing between users.

Contrary to what was observed in Germany, where 
emergency admissions decreased by $44.7 \% \pm 0.7 \%$ during the pandemic, we observed an increase of $30 \%$ in medical evaluations in our emergency department. ${ }^{65}$ The number of neurosurgical beds was significantly decreased (approximately a $70 \%$ reduction at our center), which is similar to a report from Europe ${ }^{66}$ This may be due to large neurosurgery centers in Mexico being reconverted as COVID-19 centers, and therefore their patient populations were referred to our hospital.

In general, the relatively few changes performed in our institution in standard operating protocols could have a significant impact on disease transmission without affecting the surgical outcome of patients. The implementation of these protocols may reduce the contagion risk of medical staff. In our center, less than $10 \%$ of the medical staff and only $10.9 \%$ of all active personnel in our institution have been infected.

In addition, according to our results, $21 \%$ of neurosurgery residents were under quarantine or isolation from all other hospital residents, including neurologists, psychiatrists, and other specialties, which is comparable to what has been reported in the literature with $21.2 \%$ affected. ${ }^{67}$

It is striking that the nursing staff was the group that was more affected, accounting for $60.9 \%$ of registered cases. This high rate is probably due to the fact that nurses work at other hospitals designated as COVID-19 hospitals and the fact that there are more nurses than doctors. Moreover, nurses come in close contact more frequently and closely than do doctors. Unfortunately, due to the lack of data, it was not possible to compare the size of our nursing staff with that of other centers, which was also the same case with hospital support staff (e.g., administrative staff, stretcher bearers, and nutritionists).

On the other hand, there were only 18 COVID-19-positive patients who required emergency surgery since the start of the pandemic, demonstrating that the measures we implemented were quite successful, especially taking into account that we provide an average of 10 neurosurgical emergency evaluations per day.

The flexibility to modify or readapt these protocols will allow us to prepare ourselves for the next steps in the epidemiological COVID-19 situation in Mexico, which the government has referred to as "the new normal." ${ }^{6}$

\section{Conclusions}

Our institution represents a highly specialized center for complex neurosurgical pathologies and neurosurgical training in Mexico and Latin America. We provide various pandemic response interventions undertaken by our country for consideration in response to future pandemics or, in the short term, further peaks in the COVID-19 pandemic. Because our center is not a designated COVID-19 center, we have prepared ourselves to face this pandemic, adapting our resources like most centers in Latin America and the rest of the world. The situation is ever changing, and the pandemic's behavior is evolving constantly, highlighting the importance of being creative and adaptable to every possible scenario. Our goal is to promote the protection of our staff while keeping our neurosurgical service functional. These practical and simple actions are remark- ably relevant in the context of the COVID-19 pandemic and can be adopted and tailored by other healthcare centers according to their available resources to better prepare for future crises.

\section{References}

1. WHO Coronavirus Disease (COVID-19) Dashboard. World Health Organization. Accessed May 26, 2020. https://covid19. who.int/

2. Zhu N, Zhang D, Wang W, et al. A novel coronavirus from patients with pneumonia in China, 2019. N Engl J Med. 2020; 382(8):727-733.

3. Ghebreyesus TA. WHO Director-General's opening remarks at the media briefing on COVID-19 - 20 May 2020. World Health Organization. Accessed October 23, 2020. https://www. who.int/dg/speeches/detail/who-director-general-s-openingremarks-at-the-media-briefing-on-covid-19---20-may-2020

4. Redacción. Confirman los primeros casos de coronavirus en México. BBC News Mundo. February 29, 2020. Accessed October 23, 2020. https://www.bbc.com/mundo/noticiasamerica-latina-51677751

5. Cabrera Martínez J. ¿Quién es el ingeniero contagiado de coronavirus? El Universal. Published February 28, 2020. Accessed October 23, 2020. https://www.eluniversal.com. $\mathrm{mx} /$ estados/sinaloa-quien-es-el-ingeniero-contagiado-decoronavirus

6. Ssa confirma primera muerte por coronavirus en México. Político.mx. March 18, 2020. Accessed May 26, 2020. https: //politico.mx//minuta-politica/minuta-politica-gobiernofederal/ssa-confirma-primera-muerte-por-coronavirus-en$\mathrm{m} \% \mathrm{C} 3 \% \mathrm{~A} 9 \mathrm{xico} /$

7. COVID-19 Tablero México. Gobierno de México. Accessed May 26, 2020. http://datos.covid-19.conacyt.mx/index.php

8. Burke JF, Chan AK, Mummaneni V, et al. Letter: The Coronavirus Disease 2019 global pandemic: a neurosurgical treatment algorithm. Neurosurgery. 2020;87(1):E50-E56.

9. Chinazzi M, Davis JT, Ajelli M, et al. The effect of travel restrictions on the spread of the 2019 novel coronavirus (COVID-19) outbreak. Science. 2020;368(6489):395-400.

10. Wilder-Smith A, Chiew CJ, Lee VJ. Can we contain the COVID-19 outbreak with the same measures as for SARS? Lancet Infect Dis. 2020;20(5):e102-e107.

11. Chan JF-W, Yuan S, Kok K-H, et al. A familial cluster of pneumonia associated with the 2019 novel coronavirus indicating person-to-person transmission: a study of a family cluster. Lancet. 2020;395(10223):514-523.

12. Li Q, Guan X, Wu P, et al. Early transmission dynamics in Wuhan, China, of novel coronavirus-infected pneumonia. $N$ Engl J Med. 2020;382(13):1199-1207.

13. Li Y-C, Bai W-Z, Hashikawa T. The neuroinvasive potential of SARS-CoV2 may play a role in the respiratory failure of COVID-19 patients. J Med Virol. 2020;92(6):552-555.

14. Whitcroft KL, Hummel T. Olfactory dysfunction in COVID-19: diagnosis and management. JAMA. 2020; 323(24):2512-2514.

15. De Biase G, Freeman W, Elder B, et al. Path to reopening surgery in the COVID-19 pandemic: neurosurgery experience. Mayo Clin Proc Innov Qual Outcomes. 2020;4(5):557-564.

16. Wu Z, McGoogan JM. Characteristics of and important lessons from the Coronavirus Disease 2019 (COVID-19) outbreak in China: summary of a report of 72314 cases from the Chinese Center for Disease Control and Prevention. JAMA. 2020;323(13):1239-1242.

17. Hill CS, Muirhead WR, Vakharia VN, et al. An exit strategy for resuming nonemergency neurosurgery after Severe Acute Respiratory Syndrome Coronavirus 2: a United Kingdom perspective. World Neurosurg. 2020;140:e395-e400.

18. Patel ZM, Fernandez-Miranda J, Hwang PH, et al. Letter: Pre- 
cautions for endoscopic transnasal skull base surgery during the COVID-19 pandemic. Neurosurgery. 2020;87(1):E66-E67.

19. COVID-19: Recommendations for management of elective surgical procedures. American College of Surgeons. March 13, 2020. Accessed October 23, 2020. https://www.facs.org/ covid-19/clinical-guidance/elective-surgery

20. COVID-19: Guidance for triage of non-emergent surgical procedures. American College of Surgeons. March 17, 2020. Accessed October 23, 2020. https://www.facs.org/covid-19/ clinical-guidance/triage

21. American Hospitals Association. AHA Letter to Surgeon General re: elective surgeries and COVID-19. March 15, 2020. Accessed May 26, 2020. https://www.aha.org/ lettercomment/2020-03-15-aha-letter-surgeon-general-reelective-surgeries-and-covid-19

22. Jean WC, Ironside NT, Sack KD, et al. The impact of COVID-19 on neurosurgeons and the strategy for triaging non-emergent operations: a global neurosurgery study. Acta Neurochir (Wien). 2020;162(6):1229-1240.

23. Germanò A, Raffa G, Angileri FF, et al. Coronavirus Disease 2019 (COVID-19) and neurosurgery: literature and neurosurgical societies recommendations update. World Neurosurg. 2020;139:e812-e817.

24. Gupta P, Muthukumar N, Rajshekhar V, et al. Neurosurgery and neurology practices during the novel COVID-19 pandemic: a consensus statement from India. Neurol India. 2020; 68(2):246-254.

25. Núñez-Velasco S, Mercado-Pimentel R, Ochoa-Plascencia M, et al. Response to SARS-CoV-2 pandemic in a nonCOVID-19 designated Latin-American neurosurgery department. World Neurosurg. 2020:142:506-512.

26. European Association for Neurosurgical Societies. EANS advice: Triaging non-emergent neurosurgical procedures during the COVID-19 outbreak. Accessed October 23, 2020. https:// cdn.ymaws.com/www.eans.org/resource/resmgr/documents/ corona/eans_advice2020_corona.pdf

27. Grasso G, Munakomi S. Neurosurgical practice at the time of COVID-19. World Neurosurg. 2020;138:565-566.

28. Zhao J, Rudd A, Liu R. Challenges and potential solutions of stroke care during the Coronavirus Disease 2019 (COVID-19) outbreak. Stroke. 2020;51(5):1356-1357.

29. Zou J, Yu H, Song D, et al. Advice on standardized diagnosis and treatment for spinal diseases during the Coronavirus Disease 2019 pandemic. Asian Spine J. 2020;14(2):258-263.

30. Bernucci C, Brembilla C, Veiceschi P. Effects of the COVID-19 outbreak in Northern Italy: perspectives from the Bergamo Neurosurgery Department. World Neurosurg. 2020;137:465-468.e1.

31. Lee ZD, Chyi Yeu DL, Ang BT, et al. Editorial. COVID-19 and its impact on neurosurgery: our early experience in Singapore. J Neurosurg. 2020;133(1):24-25.

32. World Health Organization. COVID-19 situation reports. Accessed May 26, 2020. https://www.who.int/emergencies/ diseases/novel-coronavirus-2019/situation-reports

33. Ti LK, Ang LS, Foong TW, Ng BSW. What we do when a COVID-19 patient needs an operation: operating room preparation and guidance. Can J Anaesth. 2020;67(6):756-758.

34. Joubert C, Desse N, Bernard C, et al. Indirect effects of the COVID19 pandemic in patients requiring neurosurgical care: will the second wave carry more severe neurosurgical patients? Br J Neurosurg. Published online June 30, 2020. doi:10.1080/02688697.2020.1782835.

35. Reed LK, Wen J, Liang B, et al. Safely performing neurosurgical procedures during COVID-19 pandemic. Neurol Res. 2020;42(10):811-817.

36. Iorio-Morin C, Hodaie M, Sarica C, et al. Letter: The risk of COVID-19 infection during neurosurgical procedures: a review of Severe Acute Respiratory Distress Syndrome Coronavirus 2 (SARS-CoV-2) modes of transmission and proposed neurosurgery-specific measures for mitigation. Neurosurgery. 2020;87(2):E178-E185.
37. Cook TM, El-Boghdadly K, McGuire B, et al. Consensus guidelines for managing the airway in patients with COVID-19: Guidelines from the Difficult Airway Society, the Association of Anaesthetists the Intensive Care Society, the Faculty of Intensive Care Medicine and the Royal College of Anaesthetists. Anaesthesia. 2020;75(6):785-799.

38. Wax RS, Christian MD. Practical recommendations for critical care and anesthesiology teams caring for novel coronavirus (2019-nCoV) patients. Can J Anaesth. 2020;67(5): $568-576$

39. Jewett DL, Heinsohn P, Bennett C, et al. Blood-containing aerosols generated by surgical techniques: a possible infectious hazard. Am Ind Hyg Assoc J. 1992;53(4):228-231.

40. Küçükdurmaz F, İmren Y, Akkoyunlu Y, et al. Domestic electric drills in the service of orthopaedic surgery: a potential and preventable source of surgical site infections. Acta Orthop Traumatol Turc. 2012;46(6):455-459.

41. Wenner L, Pauli U, Summermatter K, et al. Aerosol generation during bone-sawing procedures in veterinary autopsies. Vet Pathol. 2017;54(3):425-436.

42. Barrett WL, Garber SM. Surgical smoke: a review of the literature. Is this just a lot of hot air? Surg Endosc. 2003;17(6): 979-987.

43. Pierce JS, Lacey SE, Lippert JF, et al. Laser-generated air contaminants from medical laser applications: a state-of-thescience review of exposure characterization, health effects, and control. J Occup Environ Hyg. 2011;8(7):447-466.

44. Preston JK, Masciopinto J, Salamat MS, Badie B. Tumour cell dispersion by the ultrasonic aspirator during brain tumour resection. Br J Neurosurg. 1999;13(5):486-489.

45. Pandey AS, Ringer AJ, Rai AT, et al. Minimizing SARS CoV-2 exposure when performing surgical interventions during the COVID-19 pandemic. J Neurointerv Surg. 2020; 12(7):643-647.

46. Tao KX, Zhang BX, Zhang $\mathrm{P}$, et al. Recommendations for general surgery clinical practice in novel coronavirus pneumonia situation. Article in Chinese. Zhonghua Wai Ke Za Zhi. 2020;58(0):E001.

47. Aminian A, Safari S, Razeghian-Jahromi A, et al. COVID-19 outbreak and surgical practice: unexpected fatality in perioperative period. Ann Surg. 2020;272(1):e27-e29.

48. Lewis CT, Zeineddine HA, Esquenazi Y. Challenges of neurosurgery education during the Coronavirus Disease 2019 (COVID-19) pandemic: a U.S. perspective. World Neurosurg. 2020;138:545-547.

49. Bambakidis NC, Tomei KL. Editorial. Impact of COVID-19 on neurosurgery resident training and education. J Neurosurg. 2020;133(1):10-11.

50. Carter BS, Chiocca EA. Editorial. COVID-19 and academic neurosurgery. J Neurosurg. 2020;133(1):8-9.

51. Goyal A, Kerezoudis P, Yolcu YU, et al. Letter to the editor: Survey of academic U.S. programs regarding the impact of the COVID-19 pandemic on clinical practice, education, and research in neurosurgery. World Neurosurg. 2020;140: 476-478.

52. Szmuda T, Ali S, Słoniewski P. Telemedicine in neurosurgery during the novel coronavirus (COVID-19) pandemic. Neurol Neurochir Pol. 2020;54(2):207-208.

53. Dawoud RA, Philbrick B, McMahon JT, et al. Letter to the editor "Virtual neurosurgery clerkship for medical students." World Neurosurg. 2020;139:456-459.

54. Zoia C, Raffa G, Somma T, et al. COVID-19 and neurosurgical training and education: an Italian perspective. Acta Neurochir (Wien). 2020;162(8):1789-1794.

55. Comisión Coordinadora de Institutos Nacionales de Salud y Hospitales de Alta Especialidad. COVID-19. Gobierno de México. Accessed October 23, 2020. http://www.gob.mx/ insalud/articulos/covid-19-240047?idiom=es

56. World Health Organization. Global surveillance for 
COVID-19 caused by human infection with COVID-19 virus: interim guidance, 20 March 2020. Published online 2020. Accessed May 26, 2020. https://apps.who.int/iris/ handle/10665/331506

57. Sociedad Mexicana de Cirugía Neurológica. Breve Guía de Sugerencias Para el Manejo de las Urgencias Neuroquirúrgicas y de Medidas Ideales de Bioseguridad y Protección Durante la Pandemia de COVID-19, 2020 de la Sociedad Mexicana de Cirugía Neurológica A.C. (SMCN). Published online April 4, 2020. Accessed October 23, 2020. https://senec.es/wp-content/uploads/2020/04/MexicoActualizado-Urgencias-Covid.pdf

58. Prokop M, van Everdingen W, van Rees Vellinga T, et al. CO-RADS: A categorical CT assessment scheme for patients suspected of having COVID-19-definition and evaluation. Radiology. 2020;296(2):E97-E104.

59. Li Y, Xia L. Coronavirus disease 2019 (COVID-19): role of chest CT in diagnosis and management. AJR Am J Roentgenol. 2020;214(6):1280-1286.

60. Sharma D, Rasmussen M, Han R, et al. Anesthetic Management of Endovascular Treatment of Acute Ischemic Stroke During COVID-19 Pandemic: Consensus Statement From Society for Neuroscience in Anesthesiology \& Critical Care (SNACC): Endorsed by Society of Vascular \& Interventional Neurology (SVIN), Society of NeuroInterventional Surgery (SNIS), Neurocritical Care Society (NCS), European Society of Minimally Invasive Neurological Therapy (ESMINT) and American Association of Neurological Surgeons (AANS) and Congress of Neurological Surgeons (CNS) Cerebrovascular Section. J Neurosurg Anesthesiol. 2020;32(3):193-201.

61. Clinical Management of Severe Acute Respiratory Infection When COVID-19 Is Suspected. World Health Organization; 2020. Accessed May 26, 2020. https://apps.who.int/iris/ handle/10665/331446

62. Meng L, Qiu H, Wan L, et al. Intubation and ventilation amid the COVID-19 outbreak: Wuhan's experience. Anesthesiology. 2020;132(6):1317-1332.

63. Tan Y-T, Wang J-W, Zhao K, et al. Preliminary recommendations for surgical practice of neurosurgery department in the central epidemic area of 2019 coronavirus infection. Curr Med Sci. 2020;40(2):281-284.

64. Qureshi AI, French BR, Siddiq F, et al. COVID-19 screening with chest $\mathrm{CT}$ in acute stroke imaging: a clinical decision model. J Neuroimaging. 2020;30(5):617-624.

65. Krenzlin $\mathrm{H}$, Bettag $\mathrm{C}$, Rohde $\mathrm{V}$, et al. Involuntary ambulatory triage during the COVID-19 pandemic-a neurosurgical perspective. PLoS One. 2020;15(6): 0234956.

66. Mathiesen T, Arraez M, Asser T, et al. A snapshot of European neurosurgery December 2019 vs. March 2020: just before and during the Covid-19 pandemic. Acta Neurochir (Wien). 2020;162(9):2221-2233.
67. Alhaj AK, Al-Saadi T, Mohammad F, Alabri S. Neurosurgery residents' perspective on COVID-19: knowledge, readiness, and impact of this pandemic. World Neurosurg. 2020; 139:e848-e858.

68. D'Amico RS, Baum G, Serulle Y, et al. A roadmap to reopening a neurosurgical practice in the age of COVID-19. World Neurosurg. 2020;139:289-293.

\section{Disclosures}

The authors report no conflict of interest concerning the materials or methods used in this study or the findings specified in this paper.

\section{Author Contributions}

Conception and design: Gómez-Amador, Díaz-Bello, HernándezHernández, Mondragón-Soto, González-Aguilar, Calleja-Castillo, Mejía-Pérez, Cárdenas. Acquisition of data: Díaz-Bello, ChávezPiña, Pando-Tarín. Analysis and interpretation of data: GómezAmador, Díaz-Bello, Guinto-Nishimura, Mondragón-Soto, González-Aguilar, Leyva-Rendón, Cárdenas. Drafting the article: Gómez-Amador, Díaz-Bello, Hernández-Hernández, MondragónSoto, Cárdenas. Critically revising the article: Gómez-Amador, Díaz-Bello, Guinto-Nishimura, Mejía-Pérez. Reviewed submitted version of manuscript: Gómez-Amador, Díaz-Bello, Hernández-Hernández, Guinto-Nishimura, Mondragón-Soto, Lem-Carrillo, González-Aguilar, Taboada-Barajas, ZavalaÁlvarez, Soto-Hernández, Cárdenas. Approved the final version of the manuscript on behalf of all authors: Gómez-Amador. Administrative/technical/material support: Gómez-Amador, DíazBello, Hernández-Hernández, Leyva-Rendón. Study supervision: Gómez-Amador, Díaz-Bello, Guinto-Nishimura, GonzálezAguilar, Calleja-Castillo, Leyva-Rendón, León-Ortiz, Cárdenas.

\section{Supplemental Information}

\section{Online-Only Content}

Supplemental material is available online.

Supplemental Table 1. https://thejns.org/doi/suppl/10.3171/ 2020.9.FOCUS20553.

\section{Correspondence}

Juan L. Gómez-Amador: Instituto Nacional de Neurología y Neurocirugía "Manuel Velasco Suárez," Mexico City, Mexico. jlga@neurocirugia-innn.com. 